\title{
Evaluation of Patient Satisfaction with Nursing Care at Two Public Hospitals in Kenya: An Interventional Study
}

\author{
Githemo Grace $\mathrm{K}^{1 *}$, Karani $\mathrm{AK}^{2}$, Ogutu $\mathbf{M}^{2}$ and Gachoka $\mathrm{H}^{3}$ \\ ${ }^{1}$ Kenyatta University, Kenya \\ ${ }^{2}$ University of Nairobi, Kenya \\ 3Jomo Kenyatta University of Agriculture and Technology, Kenya
}

Research Article

Volume 2 Issue 4

Received Date: May 14, 2018

Published Date: June 25, 2018

*Corresponding author: Githemo Grace, Kenyatta University, 43844-00100, Kenya, Tel: +254 722 787862; Email: githemo.grace@ku.ac.ke

\section{Abstract}

Introduction: Patients' satisfaction with nursing care has been reported as the most important predictor of the overall satisfaction with hospital care. However, measuring patient satisfaction within health care settings still needs more emphasis. This is mainly because, as in other organizations and sectors, surveys have tended to focus on managers' and clinician's agendas and not on questions meaningful to patients which can be translated into actions.

Study Design and Objectives: This quasi experimental study aimed at evaluating the level of patient satisfaction with quality of nursing in two public hospitals in Kenya after the nurses were trained on the use of the nursing process and nursing theory in patient care with an emphasis on patient participation in care. Structured self-administered questionnaires and a Likert like scale were used to collect data which analyzed by use of SPSS. Descriptive statistics were used in data presentation. Chisquare test of significance was used to determine the difference between pre-test and posttest while logistic regression analysis was used to predict the determinants of satisfaction at post-test.

Findings: The findings showed a significant difference $(\mathrm{p}<0.05)$ between pre-test and post-test on the level of patient satisfaction with the variables evaluated. Logistic regression findings showed that females were more likely to be satisfied with the introduction they received in the ward (OR1.82,95\%CI1.074-3.3098) compared to their male counter parts. Also patients with primary level of education were less likely to be satisfied with the information received on introduction (OR 0.568,95\%CI0.334-0.967).

Conclusion: The study concluded that Majority of the patients in both study groups were satisfied with the information received on admission, satisfied with orientation and with the overall quality of nursing care they received. Also the level of education influenced patients' perception of individualized quality care. Therefore equipping patients with education can help them understand their health care needs and also appreciate quality when it's provided.

Keywords: Quality; Patient satisfaction; Nursing theory; Nursing process 


\section{Nursing \& Healthcare International Journal}

\section{Introduction}

One of the most critical quality management concepts is the customer satisfaction and therefore its importance in the quest of quality cannot be underestimated. Studies have shown that dissatisfied customers talk more than satisfied customers [1]. Therefore addressing the needs of the customer is critical since quality is usually measured from the customers' perspective. However, measuring patient satisfaction within health care settings has been limited. This is mainly because, as in other organizations and sectors, surveys have tended to focus on managers' and clinician's agendas and not on questions meaningful to patients which can be translated into actions [2]. Therefore addressing quality from a patient's perspective is critical in the health care.

Marquis [3] argues that one of the greatest measures of quality is how an organization meets customer expectations and needs. Therefore nurse leaders play a major role in the efforts to provide quality and must understand consumer quality expectations and ensure that they meet and exceed those expectations. Arije [4] added that there has been a strong focus on measurement of patient satisfaction and consumer behavior recently in the developed countries. This is because of increased awareness of the rights of users of health services as well as availability of several alternatives of where to receive healthcare. She further emphasized that People are more likely too pt for services they perceive as having better quality and thus able to meet their needs.

Several studies have been carried out to determine the factors that can lead to patient satisfaction or dissatisfaction. A Study carried out in rural Bangladesh found out that the most powerful predictor for client satisfaction with services was provider attitude or behavior, especially showing respect and politeness for patients [5].

Similarly a study carried out in Tanzania Mwananyama hospital to determine patients level of satisfaction with the quality of care found out that patients were dissatisfied with the quality of career specially hospital on communication skills in showing compassion, politeness and active listening, availability of essential drugs, and improvement on clinicians' prescription skills. They concluded that having a policy to address the above issues would in directly improve patients satisfaction and hence quality of care [6].

A study carried out in New Delhi India to determine the client's satisfaction and perception about health care quality at a primary care center revealed that participants identified several factors that were detrimental to effective delivery of quality health care. These included the perceived poor attitude of some health workers, long waiting times and high cost of services. Other hindrances to quality care identified were inadequate staff, policy of payment for health services, frequent referrals to other hospitals and lack of ambulances at facilities to transport the patients [5].

The nursing process as a tool for provision of care provides a means for evaluating the quality of nursing care that is given to the patients. Therefore it can be used in demonstrating nurses' accountability and responsibility while providing quality care to the client. The nursing process is the foundation and organizational frame work that guides professional nursing practice. Professionally, the nursing process is recognized as a model on which nursing standards are based and remains the universally accepted method of scientific nursing practice [7].

\section{Nursing Process}

Application of the nursing process in patient care had been accredited as fundamental for quality nursing care provision and nurses must be knowledgeable about its use. However a study carried out in a Brazilian hospital revealed that nurses had difficulties in the application of all the steps of the nursing process. Also the study showed that the nursing process was viewed as a documentation activity and its methodology as a theoretical process [8]. In their integrated review on the application of the nursing process in the intensive care unit Oliveira, et al. [9], found out that lack of knowledge is the main factor that hinder nurses to implement the nursing process. This is because most of them are not aware of its importance and therefore do not adhere to its application in the management of patients assigned to them.

A study carried out in Naivasha hospital Kenya, to evaluate the implementation of the nursing process found out that nurses had difficulties performing all the phases of the nursing process. These steps included; assessment, diagnosing, goal identification, planning, implementing, evaluation and documentation). Surprisingly the nurses had reported that they find all of them easy [10].

\section{Nursing Process and Nursing Theory}

Nursing can be likened to a package of goods which is to be delivered. The package or nursing itself is the model which guides the process and contains the components of which nursing is made (Pearson and Allan, 2005). A 


\section{Nursing \& Healthcare International Journal}

nursing model represents what nursing actually is. It represents the actual services which are to be delivered to the patient. Since all goods require a vehicle through which they are to be delivered, then the nursing process serves this function [11].

Therefore for nurses to effectively deliver quality patient centered care, they need to incorporate the nursing theories to nursing process. This will provide a holistic view of the patient by taking into consideration the psychological, social, cultural, and economic differences between individuals. Nursing theories will also prevent the nurses from basing the nursing process on the biomedical model which emphasis restoration of the altered pathophysiology but does not consider the whole person.

A theory that focused on the role of the nurse and the patient with a view to enhance patient involvement in the care was developed by Dorothea Orem in 1959. According to Meleis [12], Orem's theoretical model focused not just on the role of the nurse in care but also the patient hence emphasizing the role of each during the recovery process.

The application of the nursing process based on theoretical models to guide nursing practice in Kenya has received a lot of emphasis. In the 2008-2013 Strategic plan by the Division of Nursing (Ministry of Health), the implementation of models to guide practice at the facility and community based nursing services was identified. This was with an aim of shifting the nursing practice from the medical model which has influenced the practice of nursing to more comprehensive nursing model. The models identified to guide the practice were the Virginia Handerson or Dorothea Orem. Others that could be applied in different circumstances were Roy's Adaptation Model, Roger's Holistic Care Concepts, Betty Neuman's Health Care Systems Model, and Hildegard Peplau's Interpersonal Relationship Model. However their implementation in practice has been slow.
Therefore this study aimed at establishing whether the application of nursing process and its integration to the Orem's theoretical model which emphasizes patient's selfcare would have an effect on the patient satisfaction of nursing care that is provided to patients in two public Hospitals in Kenya.

\section{Study Methodology}

\section{Study Design}

This was a quasi-field experimental study since it was carried out in a natural environment in which work goes on as usual, that is Kiambu Hospital and Thika Hospital. To maintain internal validity, the study involved both pretest and post-test design with both an experimental and a control group. During the pretest stage, data was collected from the patients to establish their level of satisfaction with the quality of nursing care. At the intervention stage, nurses were trained on the nursing process and the application of Orem's theory to the steps of the nursing process which emphasized on patient participation in nursing care. During the post-test data was once again collected from the patients to establish their level of satisfaction with the quality of nursing care.

\section{Patients' Sampling}

Stratified random sampling was used to select the patients in each ward. This was done in proportion to the total number in various strata/number of patients for each ward as shown in The Fisher's formula (as recorded by Mugenda and Mugenda 2003) was used to determine the sample size To get equal representation of the sample in each ward, the sample size was calculated using the ratios of average number of patients daily in the study hospital with the total sample as the multiplication factor as shown in Tables $1 \& 2$.

\begin{tabular}{|c|c|c|}
\hline Wards/Units & Average No. of Patients Daily & Sample Size \\
\hline Male Surgical & 37 & 24 \\
\hline Female Surgical & 32 & 21 \\
\hline Male Medical & 27 & 17 \\
\hline Female Medical & 23 & 15 \\
\hline Pediatrics ward & 74 & 48 \\
\hline Gynaecology Ward & 17 & 11 \\
\hline Total & $\mathbf{2 1 0}$ & $\mathbf{1 3 6}$ \\
\hline
\end{tabular}

Table 1: Kiambu Hospital patients sample size. 


\section{Nursing \& Healthcare International Journal}

\begin{tabular}{|c|c|c|c|}
\hline Wards/Units & Average No. of Patients Daily & Calculation of The Sample Size & Sample Size \\
\hline Male Surgical & 41 & $41 / 207 \times 134$ & 26 \\
\hline Female Surgical & 24 & $24 / 207 \times 134$ & 16 \\
\hline Male Medical & 26 & $26 / 207 \times 134$ & 17 \\
\hline Female Medical & 28 & $28 / 207 \times 134$ & 18 \\
\hline Pediatrics ward & 65 & $65 / 207 \times 134$ & 42 \\
\hline Gynaecology Ward & 23 & $23 / 207 \times 134$ & 15 \\
\hline Total & $\mathbf{2 0 7}$ & & $\mathbf{1 3 4}$ \\
\hline
\end{tabular}

Table 2: Thika Hospital patients sample size.

\section{Data Analysis}

Analysis was performed by use of computer software statistical package for social scientists (SPSS version 22). Descriptive statistics was used to summarize the qualitative data in order to give meaning to the information and for easy presentation and interpretation. Chi square test of significance was used to determine the relationships between the categorical outcome variables and in hypothesis testing. (Level of significance was set at $\mathrm{p}<0.05$ ). Logistic regression analysis was used to evaluate the predictability of the changes on the level of satisfaction on the study variables.

\section{Ethical Considerations}

Authority to carry out the study was obtained from the Ministry of medical service, Ministry of Education Science and Technology, Kenyatta National Hospital/University of Nairobi ethics and research committee and Kiambu \& Thika District hospital Medical superintendents. Individual consent was obtained from the study subjects who signed the consent before answering the questionnaires. Confidentiality of the information obtained was maintained since the names of the study subjects were not required.

\section{Study Findings}

\section{Demographic Characteristics of the Patients}

Majority of the respondents were female constituting $62.35 \%(n=165)$ and $56.7 \%(n=148)$ in the pretest and post-test respectively. This was because the respondents from pediatric ward were mainly mothers admitted with their children and also gynaecology ward was also a female ward. Majority had been educated up primary level in both pretest and post-tests. On the number of days the patient had been in the ward, majority50.3\% $(\mathrm{n}=131)$ during the pre-test and $48.5 \%(\mathrm{n}=136)$ during the post- test had been admitted for less than five days in the ward. This is as shown in Table 3.

\begin{tabular}{|c|c|c|c|}
\hline \multirow{2}{*}{ Demographic characteristics of patients } & \multicolumn{2}{|c|}{ Study Groups } \\
\cline { 2 - 3 } & & Pre-Test\%(N) & Post-Test\%(N) \\
\hline \multirow{3}{*}{ Sex } & Male & $37.4 \%(99)$ & $43.3 \%(113)$ \\
\cline { 2 - 3 } & Female & $62.35(165)$ & $56.7 \%(148)$ \\
\hline \multirow{3}{*}{ Level of education } & University & $3.4 \%(9)$ & $3.8 \%(130)$ \\
\cline { 2 - 3 } & College & $11.75(31)$ & $18.0 \%(47)$ \\
\cline { 2 - 3 } & Secondary & $34.6 \%(92)$ & $34.1 \%(89)$ \\
\cline { 2 - 3 } & Primary & $50.3 \%(134)$ & $44.1 \%(115)$ \\
\hline \multirow{3}{*}{ Number of day in the ward } & Less than 5 days & $53.4 \%(131)$ & $48.5 \%(136)$ \\
\cline { 2 - 3 } & $6-10$ days & $19.7 \%(52)$ & $18.3 \%(48)$ \\
\cline { 2 - 3 } & $11-15$ days & $9.5 \%(25)$ & $11.1 \%(29)$ \\
\cline { 2 - 3 } & $16-20$ days & $3.5 \%(9)$ & $4.6 \%(12)$ \\
\cline { 2 - 3 } & More than 20 days & $13.9 \%(47)$ & $17.5 \%(36)$ \\
\hline
\end{tabular}

Table 3: Demographic characteristics of patients. 


\section{Nursing \& Healthcare International Journal}

\section{Patient Satisfaction with the Quality of Care}

The level of patient satisfaction with quality of care was evaluated on a five point scale. Majority of the patients in both study groups reported that they were satisfied with the information they received on admission. They also reported satisfaction with orientation they had received on admission and also with the overall quality of nursing care they received. A chisquare test of significance was used to determine the difference between pre-test and post-test. The findings showed a significant difference $(\mathrm{p}<0.05)$ between pre-test and posttest on the level of satisfaction with the greater.
Percentage of patients in the post-test reporting satisfaction with the information received on admission and the orientation they received. There was also significant difference $(\mathrm{p}<0.05)$ on whether the patients would recommend someone else to the same ward. However there was no significant difference $(p>0.05)$ on the overall satisfaction with the quality of care and on whether the patient would like to be readmitted the same ward if they fell sick again. The findings are as shown in Table 4.

\begin{tabular}{|c|c|c|c|c|}
\hline \multirow{2}{*}{\multicolumn{2}{|c|}{ Patient satisfaction }} & \multicolumn{2}{|c|}{ Study Group } & \multirow[b]{2}{*}{ Statistical Test } \\
\hline & & \multirow{2}{*}{$\begin{array}{c}\begin{array}{c}\text { Pre-Test } \\
\text { \%(n) }\end{array} \\
27.4 \%(73)\end{array}$} & \multirow{2}{*}{\begin{tabular}{|c|}
$\begin{array}{c}\text { Post-Test } \\
\text { \%(n) }\end{array}$ \\
$11.9 \%(31)$ \\
\end{tabular}} & \\
\hline \multirow{3}{*}{$\begin{array}{l}\text { Satisfied with the information received on } \\
\text { admission }\end{array}$} & Neutral & & & \multirow{3}{*}{$\begin{array}{l}\chi 2 \text { value }=77.422 \mathrm{df}=2 \\
\quad \mathrm{P}=0.000(\mathrm{p}<0.05)\end{array}$} \\
\hline & $\begin{array}{l}\text { Strongly disagree } \\
\text { and disagree }\end{array}$ & $34.6 \%(92)$ & $12.3 \%(32)$ & \\
\hline & $\begin{array}{c}\text { Strongly agree and } \\
\text { agree }\end{array}$ & $38 \%(101)$ & $75.9 \%$ (198) & \\
\hline \multirow{3}{*}{ Satisfied with orientation in the ward } & Neutral & $27.4 \%(73)$ & $11.9 \%(31)$ & \multirow{3}{*}{$\begin{array}{l}\chi 2 \text { value }=77.422 \mathrm{df}=2 \\
\quad \mathrm{P}=0.000(\mathrm{p}<0.05)\end{array}$} \\
\hline & $\begin{array}{l}\text { Strongly } \\
\text { disagree and } \\
\text { disagree }\end{array}$ & $34.6 \%(92)$ & $12.3 \%(32)$ & \\
\hline & $\begin{array}{l}\text { Strongly agree and } \\
\text { agree }\end{array}$ & $38 \%(101)$ & $75.9 \%$ (198) & \\
\hline \multirow{3}{*}{$\begin{array}{l}\text { I feel satisfied with the quality of nursing } \\
\text { care have received }\end{array}$} & Neutral & $15.4 \%(41)$ & $20.3 \%(53)$ & \multirow{3}{*}{$\begin{array}{l}\chi 2 \text { value }=2.929 \mathrm{df}=2 \\
P=0.231(p>0.05)\end{array}$} \\
\hline & $\begin{array}{l}\text { Strongly disagree } \\
\text { and disagree }\end{array}$ & $12.8 \%(34)$ & $14.6 \%(38)$ & \\
\hline & $\begin{array}{l}\text { Strongly agree and } \\
\text { agree }\end{array}$ & $71.8 \%(191)$ & $65.1 \%(170)$ & \\
\hline \multirow{3}{*}{$\begin{array}{l}\text { Patient would recommend someone else to } \\
\text { same ward }\end{array}$} & Neutral & $7.9 \%(21)$ & $14.9 \%(39)$ & \multirow{3}{*}{$\begin{array}{l}\chi 2 \text { value }=6.491 \mathrm{df}=2 \\
P=0.039(p<0.05)\end{array}$} \\
\hline & $\begin{array}{l}\text { Strongly disagree } \\
\text { and disagree }\end{array}$ & $18.4 \%(49)$ & $17.2 \%(45)$ & \\
\hline & $\begin{array}{l}\text { Strongly agree and } \\
\text { agree }\end{array}$ & $73.7 \%$ (196) & $67.8 \%(17)$ & \\
\hline \multirow{3}{*}{$\begin{array}{l}\text { Patient would like to be readmitted the } \\
\text { same ward if falls sick again }\end{array}$} & Neutral & $15.0 \%(40)$ & $13.0 \%(34)$ & \multirow{3}{*}{$\begin{array}{c}\chi 2 \text { value }=0.707 \mathrm{df}=2 \\
P=0.702(\mathrm{p}>0.05)\end{array}$} \\
\hline & $\begin{array}{l}\text { Strongly disagree } \\
\text { and disagree }\end{array}$ & $20.3 \%(54)$ & $22.6 \%(59)$ & \\
\hline & $\begin{array}{c}\text { Strongly agree and } \\
\text { agree }\end{array}$ & $64.7 \%(172)$ & $64.4 \%(168)$ & \\
\hline
\end{tabular}

Table 4: Patient satisfaction with the quality of care.

\section{Logistic Regression Test for Patient's Satisfaction}

Logistic regression model was used to determine predictors of patient satisfaction at post-test. The findings from the study showed that females were more likely to be satisfied with the introduction they received in the ward (OR1.82, 95\%CI1.074-3.3098) compared to their male counter parts. Also patients with primary level of education were less likely to be satisfied with the information received on introduction (OR $0.568,95 \%$ CI0.334-0.967). On the same note being in Kiam but he patient was less likely to be satisfied with the introduction (OR 0.483, 95\%CI 0.284-0.821). On the 


\section{Nursing \& Healthcare International Journal}

satisfaction with the orientation in the ward female patients were less likely to be satisfied (OR 0.428, 95\%CI

0.250-0.734). The findings areas shown in Table 5.

\begin{tabular}{|c|c|c|c|c|c|}
\hline Dependent Variable & Independent variable & $\begin{array}{c}\text { Wald } \\
\text { statistics }\end{array}$ & OR & p Value & $95 \% \mathrm{CI}$ \\
\hline \multirow{3}{*}{$\begin{array}{c}\text { Satisfaction with introduction received } \\
\text { in the ward }\end{array}$} & Level of education (Primary ref) & 4.343 & 0.568 & 0.037 & $0.334-0.967$ \\
\hline & Sex of the patient (Female ref) & 4.944 & 1.824 & 0.026 & $1.074-3.3098$ \\
\hline & Hospital (Kiambu ref) & 7.238 & 0.483 & 0.007 & $0.284-0.821$ \\
\hline \multirow{3}{*}{$\begin{array}{l}\text { Satisfaction with the information } \\
\text { received on admission }\end{array}$} & Level of education (Primary ref) & 0.004 & 0.982 & 0.949 & 0.554-1.739 \\
\hline & Sex of the patient & 0.606 & 0.796 & 0.436 & 0.449-1.413 \\
\hline & Hospital (Kiambu ref) & 0.007 & 0.976 & 0.935 & $0.551-1.731$ \\
\hline \multirow{3}{*}{ Satisfaction with orientation in the ward } & Level of education (Primary ref) & 4.504 & 1.817 & 0.034 & $1.047-3.154$ \\
\hline & Sex of the patient & 9.546 & 0.428 & 0.002 & $0.250-0.734$ \\
\hline & Hospital (Kiambu ref) & 2.404 & 0.652 & 0.121 & $0.380-1.120$ \\
\hline \multirow{3}{*}{$\begin{array}{l}\text { The nurse fully explained to me the } \\
\text { nature of my treatment }\end{array}$} & Level of education (Primary ref) & 1.223 & 1.354 & 0.269 & $0.791-2.319$ \\
\hline & Sex of the patient & 0.046 & 0.943 & 0.83 & $0.551-1.613$ \\
\hline & Hospital (Kiambu ref) & 1.009 & 1.314 & 0.314 & $0.771-2.240$ \\
\hline \multirow{3}{*}{ Satisfaction with admission in the ward } & Level of education (Primary ref) & 0.004 & 0.982 & 0.949 & $0.554-1.739$ \\
\hline & Sex of the patient & 0.606 & 0.796 & 0.436 & $0.449-1.413$ \\
\hline & Hospital (Kiambu ref) & 0.007 & 0.976 & 0.935 & $0.551-1.731$ \\
\hline \multirow{3}{*}{$\begin{array}{c}\text { Patient would recommend someone in } \\
\text { the ward }\end{array}$} & Level of education (Primary ref) & 3.71 & 1.705 & 0.054 & $0.991-2.993$ \\
\hline & Sex of the patient & 4.995 & 0.545 & 0.025 & $0.320-0.928$ \\
\hline & Hospital (Kiambu ref) & 0.471 & 0.83 & 0.492 & $0.487-1.414$ \\
\hline \multirow{3}{*}{$\begin{array}{l}\text { Patient would like to be readmitted in } \\
\text { the ward }\end{array}$} & Level of education (Primary ref) & 2.516 & 1.528 & 0.113 & $0.905-2.580$ \\
\hline & Sex of the patient & 5.029 & 0.553 & 0.025 & $0.329-0.928$ \\
\hline & Hospital (Kiambu ref) & 0.063 & 0.936 & 0.936 & 0.557-1.571 \\
\hline
\end{tabular}

Table 5: Logistic regression test for patient satisfaction.

\section{Discussion}

Patients' satisfaction with nursing care has been reported as the most important predictor of the overall satisfaction with hospital care and an important goal of any healthcare organization [13]. The findings of the current study revealed that Majority of the patients in both study groups were satisfied with the information received on admission, satisfied with orientation and with the overall quality of nursing care they received.

This compares with findings of a study done in Tehran hospital in Iran that revealed that a vast majority (82.8\%) of the respondents were satisfied with almost all aspects of nursing care they received [13]. The findings are also compare able to a study carried out in Jordan that revealed that $77 \%$ of the respondents were satisfied with the care they were receiving from Nurses [14].

A study in Brazil showed similar findings on the patients' perspectives towards the nursing care they were receiving. The study revealed high level of patient satisfaction with the care they were receiving from the nurses in all the nursing domains evaluated [15]. Therefore satisfaction of the external customers (in this case patient) is key to quality healthcare outcomes that management should critically look at.

According to Kenya Institute of management [1], one of the most critical quality management concepts is the customer satisfaction and therefore its importance in the quest of quality cannot be under estimated. Studies have 


\section{Nursing \& Healthcare International Journal}

shown that dissatisfied customers talk more than satisfied customers. Therefore addressing the needs of the customer is critical since quality is usually measured from the customers' perspective. Marquis [3] also added that a key quality indicator is meeting and even exceeding customer expectations especially in health care institutions where in most cases the purchaser of the services is rarely the consumer.

Logistic regression used to evaluate the predictors of patient satisfaction. The study found out that patients with primary level of education were less likely to be satisfied with the information received on introduction (OR0.568,95\%CI0.334-0.967). This could be attributed to their low level of education and in ability to know their rights. These findings compares with the results of a study carried out in Germany which found out that what influenced patients perception of individualized quality care was their level of education and the perceived decision-making process $[16,17]$.

Arije [4] also found out that when consumers of health care were aware of their rights and provided with several alternatives on where to receive health care, they tended to opt for services they perceived to be of high quality and this improved their satisfaction. Therefore ensuring an educated population and providing the information required for patients to make informed decisions would enhance their perception of quality and also appreciate it.

\section{Conclusions}

The findings of the current study revealed that Majority of the patients in both study groups were satisfied with the information received on admission, satisfied with orientation and with the overall quality of nursing care they received. Also the level of education influenced patients' perception of individualized quality care. Therefore equipping patients with education can help them understand their health care needs and also appreciate quality when it is provided

\section{References}

1. KIM (2009) Total quality management theory, concepts and practice Moran (EA) Nairobi, Kenya.

2. Devkaran S (2014) Patient experience is not patient satisfaction: understanding the fundamental differences 1-48.
3. Marquis B (2012) Leadership roles and management functions in nursing: Theory and application, Lippincott Williams, China.

4. Arije 00 (2016) Quality in primary health care services in sub-Sahara Africa: right or privilege? Journal of Community Medicine and Primary Health 28(1): 25-30.

5. Rasheed N, Arya S, Acharya A (2012) Client Satisfaction and Perceptions About Quality of Health Care at a Primary Health Centre of Delhi, India. Journal of Community Health.

6. Khamis K, Njau B (2014) Patients' level of satisfaction on quality of health care at Mwananyamala hospital in Dar es Salaam, Tanzania. BMC Health Services Research 14: 400.

7. Craven RF, Hirnle CJ (2000) Fundamentals of nursing: human health and function $3^{\text {rd }}($ edn) Philadelphia: Lippincott Williams \&Wilkins.

8. Helena $M$, Moraes $B$ De, Higa $R$, José $M$, Tocoginecology M, et al. (2010) Evaluation of the nursing process used at a Brazilian teaching hospital, Int J Nurs Terminol Classif 21(3): 116-123.

9. Oliveira LS, Moura CDC (2013) Integrative Review Article Nursing Process and its Application in an Intensive Care Unit: Integrative Review 7: 41834191.

10. Mangare NL, Omondi AL, Ayieko OA, Wakasiaka S, Wagoro MCA (2016) Implementation of the Nursing Process in Naivasha District, Kenya, American Journal of Nursing Science 5(4): 152-157.

11. Pearson A, Vaughan B (2005) Nursing models for practice, $3^{\text {rd }}(\mathrm{edn})$, Butterwoth Heinmann, China.

12. Meleis A (1991) Theoretical Nursing: Development and progress, Philadelphia: Lippincott.

13. Akhtari Zavare M, Abdullah MY, Syed Hassan ST, Said S, Kamali M (2010) Patient satisfaction: evaluating nursing care for patients hospitalized with cancer in Tehran teaching hospitals, Iran. Global Journal of Heath Science 2(1): 117-126.

14. Alasad JA, Ahmad MM (2003) Patients' satisfaction with nursing care in Jordan. International Journal of Health Care Quality Assurance 16(6): 279-285. 


\section{Nursing \& Healthcare International Journal}

15. Freitas JS De, Silva AEBDC, Minamisava R, Bezerra ALQ, Sousa MRG De (2014) Quality of nursing care and satisfaction of patients attended at a teaching hospital. Revista Latino-Americanade Enfermagem 22(3): 454- 460.

16. Köberich S, Feuchtinger J, Farin E (2016) Factors influencing hospitalized patients' perception of individualized nursing care : a cross-sectional study. BMC Nurs 15: 14.

17. MOH (2012) Kenya Health Sector Strategic and Investment Plan.

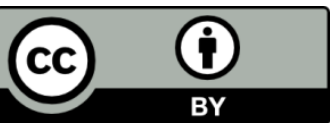

